\title{
A VARIAÇÃO LINGUÍSTICA NA HISTÓRIA EM QUADRINHOS: O ENSINO DA LÍNGUA MATERNA COM O APOIO DA HQ TURMA DA MÔNICA
}

\author{
Natália Martins Gonçalves ${ }^{1}$ \\ Lizandra de Oliveira Pereira ${ }^{1}$ \\ Jaíne Almeida Oliveira ${ }^{1}$ \\ Angélica Tiscoski Coelho ${ }^{1}$ \\ Fernanda Cizescki ${ }^{2}$
}

\section{INTRODUÇÃO}

O presente trabalho tem por finalidade compreender a representação da variação linguística no cotidiano de crianças e jovens, a partir de um estudo problematizado das estórias em quadrinhos da turma da Mônica infantil para a jovem. Tendo como objetivos específicos estabelecer conexões entre a variação linguística com a aprendizagem da língua materna, entender como a variação é representada nas estórias em quadrinhos (HQs), além de relacionar a variação linguística e a aprendizagem da língua materna, na perspectiva das HQs, considerando a Turma da Mônica.

Para Possenti (1996, p.34), "a variação linguística é o reflexo da variedade social e, como em todas as sociedades existe alguma diferença de status ou de papel entre indivíduos ou grupos, essas diferenças se refletem na língua". Jesus (2012) defende que o preconceito linguístico decorre do padrão de ensino da gramática normativa, de forma descontextualizada, de língua homogênea, ao contrário da corrente de pensadores que acreditam que as variações da linguagem deveriam ser encaradas de forma mais natural. Porém, o que se observa no ambiente das escolas é o ensino excludente da língua, sem um conhecimento sólido de teoria linguística e/ou do valor das variantes.

Geraldi (1996) argumenta que a compreensão da gramática advém de uma reflexão prévia sobre a língua, mas, ao contrário do que é ensinado pela gramática normativa, o indivíduo somente aprenderá a gramática quando ele já refletiu e compreendeu o sentido pleno da linguagem. Dessa forma, é fundamental que o ensino da língua materna respeite as variações da fala e o contexto social no

\footnotetext{
${ }^{1}$ Acadêmica do Curso de Letras Habilitação em Língua Portuguesa da Universidade do Extremo Sul Catarinense (UNESC) E-mail: ngo@unesc.net ;

${ }^{2}$ Professora do Curso de Letras Habilitação em Língua Portuguesa da Universidade do Extremo Sul Catarinense (UNESC) E-mail: fcz@unesc.net
} 
qual os indivíduos estão inseridos, evitando-se assim o preconceito linguístico (BAGNO, 2002).

A HQ é um gênero textual que combina narrativa visual e oral empregando um enredo curto. Segundo Luyten (1987, p.7), "em todas as áreas temos, portanto, a possibilidade de encontrar os quadrinhos. O que importa, porém, é de onde vêm essas histórias e quem as escreve, pois elas são excelente veículo de mensagens ideológicas e de crítica social, explícita ou implicitamente".

Logo, propõe-se com esse estudo, compreender e refletir sobre a variação linguística no aprendizado da língua materna a partir das histórias em quadrinhos, em especial a Turma da Mônica em suas séries infantil e jovem.

\section{METODOLOGIA}

A pesquisa quanto aos fins de investigação se propôs a um fim descritivo, visando compreender os conceitos e a caracterização dos fenômenos envolvendo a variação linguística, o ensino da língua materna e o uso das histórias em quadrinhos como estratégia para discutir as variantes da fala e os seus usos. A pesquisa quanto aos meios de investigação caracteriza-se como bibliográfica. Para realizá-la foi necessário buscar subsídios em artigos científicos e outras bibliografias sobre o tema, como livros e informações em websites. Foram feitas pesquisas na biblioteca da UNESC no acervo e nas bases de dados da biblioteca virtual. Os textos foram analisados de forma a embasar a possibilidade de uso das revistas em quadrinhos como apoio pedagógico par ao ensino da língua materna. Foi feito também um levantamento histórico das revistas em quadrinhos da turma da Mônica infantil, desde as primeiras criações, observando o tipo de linguagem usada pelos personagens, observando o ambiente onde eles viviam, bem como as suas comunidades de fala. Em seguida, foi feita uma comparação com as revistas da turma da Mônica Jovem. Os resultados das análises dos textos científicos encontrados em artigos e livros serviram como apoio para as considerações do uso das revistas como estratégia de ensino da língua materna, dentro de uma perspectiva da variação linguística.

\section{GÊNERO QUADRINHO (HQ)}


O surgimento da História em Quadrinho ultrapassa milênios, desde a préhistória, quando os seres humanos desenhavam nas rochas os acontecimentos do seu dia a dia, conhecidos como arte rupestre (LUYTEN, 1987).

No entanto, essa inspiração levou o norte americano Richard Outcault em 1894, a ter a primeira história em quadrinho (HQ) publicada em jornais de Nova York intitulada Yellow Kid (Menino Amarelo). O personagem, a ação dividida em quadrinhos e os balõezinhos de texto se tornaram um sucesso e um marco para a época (LUYTEN, 1987).

A partir do trabalho de Richard Outcault, as HQs se popularizaram como um gênero de comunicação de massa, além de ter contribuído para a evolução das tecnologias de impressão colorida em jornais. Como bem destaca Luyten (1987. p.10):

\begin{abstract}
Desde o início, sua característica foi a de comunicação de massa, uma vez que atingia um público enorme. Outro detalhe foi a exigência dos melhores e mais modernos processos de impressão gráfica para a sua produção. Assim, o primeiro quadrinho norte-americanos, o Yellow Kid (Moleque Amarelo), de cor amarela, foi justamente para testar essa cor que estava sendo usada pela primeira vez na impressão de jornais. No Brasil, a Editora Abril, o maior parque gráfico da América Latina, começou e se consolidou com a impressão das revistas Pato Donald.
\end{abstract}

Já no Brasil, pode-se dizer que as HQs surgiram quase na mesma época, por volta de 1869, com o caricaturista Ângelo Agostini, que criou "As Aventuras de Nhô-Quim" e "Zé Caipora", na revista Vida Fluminense, do Rio de Janeiro. Mais tarde, a partir de 1960, chegam às bancas para quem gosta desse tipo de leitura, a "Turma do Pererê", do cartunista Ziraldo e "A Turma da Mônica", de Maurício de Souza (LUYTEN, 1987).

As HQs ficaram popularmente conhecidas no Brasil como gibi, isso em referência a uma revista lançada em 1939, que caiu no gosto dos leitores de tal forma que passou a nomear as HQs em geral (LUYTEN, 1987). A autora ressalta que:

Poucas pessoas se lembram de que a palavra "gibi" significa "moleque". É que houve uma revista com este nome, nas décadas de 30 a 40, que, de tão difundida, emprestou seu nome a todas as revistas de quadrinhos do país. Na América Espanhola, usa-se a palavra "historieta", no Japão, mangá, e em Portugal, "histórias aos quadrinhos" (LUYTEN, 1987), p.11).

Podendo ser adquirido em bancas, livrarias e até mesmo na internet, os gibis dispõe de uma peculiaridade singular que são os balões, os quadros e os desenhos, tornando fácil a sua identificação. 
Mauricio de Souza lançou seu primeiro trabalho em 1959 e seu primeiro personagem ficou conhecido como Bidu, publicado pela Editora Continental. Posteriormente, publicou outros personagens em tiras na Folha de São Paulo e sua distribuição foi feita em jornais de todo o país. Somente no início dos anos de 1970 é que foram lançados pela editora Abril os personagens da "Turma da Mônica" (LUYTEN, 1987).

Luyten (1987) destaca que os personagens das HQs de Maurício de Souza alcançaram sucesso, conseguindo vender mais revistas do que as do mundo Disney no Brasil, levando o autor a um nível de reconhecimento que nenhum dos outros desenhistas nacionais conseguiu: êxito no Brasil e fama mundial. Dentre os seus personagens, o que mais se sobressaiu ao longo do tempo foi o Chico Bento, "justamente o que melhor representa o brasileiro de nossos dias com seus sonhos nostálgicos de volta ao interior" (LUYTEN, 1987, p.61).

Segundo Quintal (2010), a linguagem verbal e visual da HQ é que completa o enredo, diferenciando das narrativas cinematográficas e dos desenhos animados, pois exige maior esforço de entendimento por parte do leitor. A caracterização das HQs é bem marcada, por meio de tratamento coloquial, interjeições e reduções vocabulares, tendo como objetivo principal facilitar a compreensão do leitor.

As onomatopeias são outro recurso muito utilizado nos quadrinhos a fim de expressar sons e ruídos na língua escrita. De acordo com o dicionário Aurélio (2015), entende-se por onomatopeias um processo de formação de uma palavra cujo som imita aproximadamente o som do que significa. Esses efeitos sonoros tiveram sua origem na língua inglesa para que assim pudessem estar mais próximo da realidade. Realidade essa que consagra grandes nomes, como Maurício de Souza, em uma excelente produção brasileira de Histórias em Quadrinho (QUINTAL, 2010).

\section{VARIAÇÃO LINGUÍSTICA}

\section{A VARIAÇÃO LINGUÍSTICA NO PORTUGUÊS BRASILEIRO}

Brescancini (2007) explica que a variabilidade é uma característica inerente a qualquer sistema linguístico, sendo observada nas diversas comunidades de fala, em diferentes línguas e dialetos. Essas variações aparecem com frequência 
no português brasileiro, como por exemplo, quando os falantes realizam certas escolhas entre dois ou mais sons, vocábulos ou estruturas, como nos casos: "tu vais pra onde?", "você vai pra onde?", "tu vai onde?" e "tu vai pra onde?" (BRESCANCINI, 2015).

Romaine (2001, apud BRESCANCINI, 2007) escreve que a sociolinguística é uma área de estudo da linguística apresentada nos anos 50 por linguistas e sociólogos. Esses pensadores tinham como objetivo colocar uma perspectiva de análise sobre o lugar da língua na sociedade, em particular, o contexto social da diversidade linguística, justificando que um falante, ou grupo de falantes, pode realizar escolhas de sons, vocábulos ou estruturas na produção da linguagem. Esses estudos foram a base para as concepções da Teoria da Variação Linguística, ou Sociolinguística.

Scherre e Yacovenco (2011, p.122) escreve que:

A variação e a mudança linguística há muito são objeto de pesquisadores em vários países, mas é na década de 1960 que surge um modelo sociolinguístico forte, cuja compreensão é a de que a variação e a mudança linguísticas são inerentes ao próprio sistema, podendo ser controladas por restrições de caráter interno (estrutural) ou externo (social, contextual, discursivo etc.).

Luchesi (2012, p.793) afirma que "a sociolinguística surge como uma resposta à incapacidade do formalismo linguístico" ao assumir que a língua é heterogenia e variável. Para Britto (2004, p.148), "a unidade e a diversidade de uma língua vem do modo como a sociedade se organiza e reparte seus saberes e valores". Por isso, a sociolinguística aponta que é fundamental considerar nos estudos linguísticos um contexto social e histórico específico, definindo nesse contexto a comunidade de fala, a coletividade que usa concretamente a língua como seu objeto de pesquisa (LUCHESI, 2012). Sendo assim, Brescancini (2007, p.nd) esclarece como as comunidades de fala fazem escolhas entre sons, palavras ou estruturas:

Ficou claro a partir de então que as escolhas entre dois ou mais sons, palavras ou estruturas não ocorrem simplesmente por opção do falante, mas obedecem a um padrão sistemático regulado por regras especiais, conhecidas como regras variáveis, que expressam a covariação entre elementos do ambiente linguístico e do contexto social. 
Bertoni-Ricardo (2009) argumenta que os estudos da gramática tradicional colocam distinção entre língua padrão, dialetos e variedades de padrão. A mesma autora considera que esses preceitos podem incorrer em preconceito linguístico (ao estigmatizar certos usos de palavras e expressões por diferentes comunidades de fala) e ainda ressalta que as bases desse método tende a estabelecer fronteiras rígidas entre a língua padrão, os dialetos e as variedades de padrão quando do estudo e interpretação do português brasileiro. Nesse sentido, Bertoni-Ricardo (2009) propõe sistematizar e explicar como ocorre a variação linguística no português brasileiro, considerando três linhas chamadas de contínuos, que são:

a) Contínuo de urbanização:

No português brasileiro "no contínuo de urbanização, não existem fronteiras rígidas que separam os falares rurais ou urbanos. As fronteiras são fluídas e há muita sobreposição entre esses tipos de falares (BERTONI-RICARDO, 2009, p.53)." A Figura 1 mostra, esquematicamente em uma linha, como ocorrem as variações da língua do contexto social das comunidades nas áreas rurais geograficamente mais isoladas, como exemplo de fala típica está o personagem Chico Bento de Maurício de Souza, passando pela área rural isolada, urbana até chegar às áreas urbanas onde estão as comunidades de fala mais padronizadas. Por isso, o autor considera que existe um contínuo nesse sistema, pois não existe fronteiras rígidas entre uma comunidade de falantes e outra.

Figura 1 - O contínuo de urbanização

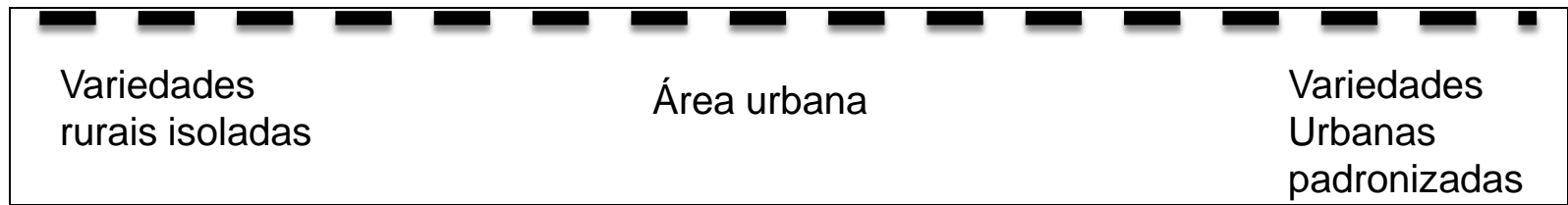

Fonte: Adaptado de Bertoni-Ricardo (2009)

$\mathrm{Na}$ área urbana estão muitos dos falantes que deixaram as zonas rurais isoladas e se mudaram para mais próximo das zonas urbanas. Esses falantes carregam consigo várias expressões e tradições de fala próprias das zonas rurais isoladas, todavia começam a assimilar os sistemas de fala da zona urbana. Em contraposição, nas áreas urbanas padronizadas se concentram as comunidades de fala provenientes de grupos sociais ligados ao comércio, à indústria, às repartições 
públicas. Conforme Bertoni-Ricardo (2009), nesses grupos sociais predominam a cultura da fala mais monitorada tanto nas manifestações escritas quanto orais, sendo essas comunidades as depositárias e implementadoras do letramento.

b) Contínuo de oralidade-letramento:

A Figura 2 ilustra o contínuo de urbanização, apontando, segundo Bertoni-Ricardo (2009), que na ponta da esquerda, onde estão as variedades rurais isoladas, predominam a oralidade, enquanto que a concentração do letramento predomina nas variedades urbanas padronizadas. Para a autora, não existem fronteiras entre o letramento e a oralidade, a variação flui de uma ponta a outra, no processo de mudança. Todavia, nas comunidades rurais isoladas geograficamente há o predomínio da oralidade, enquanto no outro extremo se concentram as comunidades de fala orientadas pelo letramento.

Figura 2 - O Contínuo de oralidade-letramento

Eventos

Eventos

de oralidade

de letramento

Fonte: Adaptado de Bertoni-Ricardo (2009)

c) Contínuo de monitoração estilística:

O contínuo de monitoração estilística se explica com base nas situações de fala de forma espontânea ou monitorada, o que leva os falantes a se pronunciarem de forma a buscar o apoio da língua padrão ou não. Os estilos de fala monitorada se impõe quando a situação assim o exige, como por exemplo, depende: do ambiente, do interlocutor e do tópico que está sendo tratado (BERTONIRICARDO, 2009). Dessa forma, esta situação pode acontecer com as diferentes comunidades de fala, a depender da ocasião.

Figura 3 - O Contínuo de de monitoração estilística

- monitoração + monitoração

Fonte: Adaptado de Bertoni-Ricardo (2009) 


\title{
A VARIAÇÃO LINGUÍSTICA EM SALA DE AULA
}

Como escreve Revuz (1998, p.219):

\begin{abstract}
Aprender a falar é, para a criança, estabelecer um compromisso, é encontrar alguma coisa para dizer do seu próprio desejo, alguma coisa dos valores que adquiriram para ela os objetos e as palavras, em uma linguagem tecida a partir do desejo do Outro, enquanto ela própria é modelada a partir desse desejo.
\end{abstract}

A variação da linguagem provoca grandes discussões entre linguistas e professores, sendo que cada indivíduo possui uma metodologia para o ensino da Língua Materna. É por esse motivo que os linguistas acharam viável um estudo sobre a maneira mais adequada de um ensino que respeite as diferenças dialetais de cada educando. Conforme aponta Bortoni-Ricardo (2009), nas últimas décadas, os educadores brasileiros, com destaque especial para os linguistas -seguindo uma corrente que nasceu da polêmica entre a postura que considera o "erro" uma deficiência do aluno e a postura que vê os chamados "erros" como uma simples diferença entre as duas variedades - têm feito um trabalho importante, mostrando que é pedagogicamente incorreto usar a incidência do erro do educando como uma oportunidade para humilhá-lo.

Segundo Bortoni-Ricardo (2009), é no momento em que o aluno usa uma regra padrão e o professor intervém, fornecendo a variante padrão, que as duas variedades, se justapõem em sala de aula. E é por esse motivo que ao "defender uma coisa não significa combater outra, pois o papel da escola é dar acesso a todas as variedades existentes, ficando a cargo da linguística descrever esses fenômenos, ajudando a entender melhor o funcionamento das línguas dando respaldo ao processo de ensino" (CALLIAN; BOTELHO, 2014, p.2). Para Bagno (2003, apud CALLIAN; BOTELHO, 2014, p.3) "a língua classificada como materna é muito diferente da norma padrão tradicional. Segundo o autor, ela é um português vivo, dinâmico que está presente em uma sociedade multifacetada".

\section{A RELAÇÃO DA VARIAÇÃO LINGUÍSTICA COM A APRENDIZAGEM DA LÍNGUA MATERNA: UMA ANÁLISE NA PERSPECTIVA DA TURMA DA MÔNICA}


Diversos estudiosos estão de acordo que a linguagem se transforma no espaço e ao longo do tempo, não havendo língua humana que permaneça uniforme (POSSENTI, 1996). Othero (2004, p.5) ressalta que "essas mudanças das línguas são, antes de tudo, adaptações aos novos usos a que seus usuários (a comunidade falante) as submetem". Além disso, as mudanças na língua ocorrem também de acordo com o contexto social, variando ainda nos usos orais e escritos, como aponta Britto (2004, p.147):

Pode-se argumentar que a norma culta, do jeito que é preconizada nas gramáticas, é apenas uma idealização, que funciona como uma espécie de lei, determinando os usos orais e escritos e servindo de referência para a correção das formas linguísticas. De fato, não é falada por quase ninguém, e mesmo as pessoas instruídas e de boa condição social erram com relação à gramática. Sua utilidade estaria em estabelecer um padrão que garantisse a unidade linguística nacional e os usos formais públicos da língua.

Othero (2004) destaca que a língua varia no tempo e no espaço para se adaptar às necessidades dos falantes, de forma a atender às exigências linguísticas da comunidade em que se está inserido, levando a modificações distintas de um lugar para outro. O mesmo autor afirma ainda que certas palavras, expressões da língua podem também entrar em desuso, tornar-se arcaicas e obsoletas, fazendo com que futuras gerações não tenham mais acesso a elas nos usos diários. Por outro lado, expressões e vocábulos também podem ser incorporados à língua através do uso recorrente e, por isso, receberem um reforço dos falantes em geral ou de certos grupos, como por exemplo o de adolescentes. Isso não significa que a língua tenha sido corrompida, pelo contrário, indica que a mesma evolui dentro do processo de transformações sociais e históricas (OTHERO, 2004).

A turma da Mônica, uma das mais comentadas histórias em quadrinhos (HQs), neste ano de 2015, completou 56 anos de existência. Durante esses anos a linguagem foi modificando, ou seja, houve uma evolução da linguagem nas HQs da Turma da Mônica (QUINTAL, (2010). A mais nova produção de Maurício de Sousa apresenta a Turma da Mônica já adolescente, tratando de temas mais sérios como, sexualidade, drogas e bebidas. A fim de cumprir com esse objetivo o universo dos cenários, personagens, brincadeiras, e principalmente o emprego da linguagem foram modificados. 
$\mathrm{Na}$ turma infantil as personagens diziam coisas como, "Meu Deus"! ou "não acredito" agora na Turma da Mônica Jovem, crescidos, as personagens preferem termos como: "oras!" "desencana" "dar uma esticada" "tô na área", o que denota que as mudanças no campo da linguagem são influenciadas pelo contexto social retratado nas histórias, refletindo a contemporaneidade em que se encontram, determinando a que público se destina. Dependendo de cada região, as linguagens podem diferir umas das outras. O Chico Bento, personagem que representa o povo do interior, das áreas rurais isoladas geograficamente, expressa essa variação. $A$ nova linguagem da Turma da Mônica é bem mais atualizada, dinâmica, curta e flexível, hà a inserção de gírias nos diálogos, formalidade e informalidade.

A Turma da Mônica na versão adolescente é representada em mangás, quadrinhos japoneses, Cebolinha antes que trocava a letra "R" pelo "L" freqüentemente, agora só troca quando está nervoso, principalmente, na frente da Mônica.

Camacho (2003, p.67 ) adverte que "tendo constatado que a linguagem varia e tendo discutido de que natureza é a variação, resta ainda avaliarmos as consequências dessas propriedades da linguagem para o ensino da língua materna." É notório que cada região do Brasil apresenta uma variação de linguagem, considerando os diferentes contextos geográficos e sociais, além de variar também nas áreas rurais e urbanas (BORTONI-RICARDO, 2009). Essa heterogeneidade é visível em salas de aula no aprendizado da Língua Materna e também é representado nas HQs da Turma da Mônica. Um exemplo dessas variações linguísticas é o Chico Bento, personagem da Turma da Mônica que mora no interior, região geograficamente isolada, com predominância da oralidade (BORTONIRICARDO, 2009). Essas variedades ocorrem por inserção de contextos sociais diversos. A escola, como uma instituição de ensino, impõe ao aluno a fala de acordo com a norma gramatical, muitas vezes ignorando a variação que advém desses contextos sociais diferentes.

A escola age muitas vezes condicionando para que a linguagem seja homogênea e sem variantes, determinando um modelo a ser seguido por todos, submetendo a variação linguística para um critério de correção. 
como se simplesmente nada dominasse, a escola parece simplesmente ignorar a variação linguística (CAMACHO, 2003, p.68).

Nesse sentido, o papel da tradicional pedagogia normativa da língua materna partindo desse pressuposto, "é que cabe à escola o papel de compensar supostas carências socioculturais" (CAMACHO, 2003, p.69). Sendo assim, a tarefa fundamental do ensino de língua materna é o de substituir a variedade não-padrão pela padrão. A sociolinguística, por outro lado, propõe que as falas diferentes da padrão que aparece com os alunos não deve ser submetida à juízos de valor por parte do professor de língua materna. Nesse sentido o ensino ao língua materna "cumpre-lhe despertar a consciência do aluno para a adequação das formas às circunstâncias do processo de comunicação" (CAMACHO, 2003, p.69).

$O$ aluno deve adequar-se ao uso de formalidades ou informalidades de acordo com a situação a que se insere. Nesse aspecto a população que vive na zona rural isolada ou nas zonas rururbanas, em zonas socialmente marginalizadas, ou que apresenta um baixo índice escolar, tem maior dificuldade para a adequação da língua, como exemplo, observa-se as variedades linguísticas existentes na Turma da Mônica, com destaque para o personagem Chico Bento, que representa o homem do campo e a fala do povo "caipira", que vive nas regiões geograficamente isoladas do Brasil. Essas pessoas que vivem no campo, muitas vezes pertencendo a grupos de baixa escolaridade e oralidade, mesmo que o Chico esteja na escola, ele continua falando "errado". Já as HQs da Turma da Mônica versão jovem usam linguagens contemporâneas, como por exemplo, as gírias, internetês e os estrangeirismos. Havendo uma evolução na linguagem, de acordo com o contexto particular social de um determinado grupo. O ensino da Língua Materna deve abordar as variações linguísticas em sala de aula, visando que o aluno saiba comunicar-se de acordo com a classe ou contexto social inserido. Maurício de Sousa enfatiza bem essa variedade de linguagem em suas HQs.

A diversidade linguística deve ser trabalhada em sala de aula para que o aluno domine o seu dialeto familiar, o do seu grupo social e a norma culta oficial do seu país, adequando-se aos diferentes contextos e evitando o preconceito linguístico. Para isso, o uso de HQs em sala de aula pode ser um apoio para se trabalhar as variações sem que se desconsidere o ensino da norma culta, considerando que ela é necessária para a vida profissional e social do aluno e imprescindível para a escrita formal. Cabe ao professor, ensinar a norma culta 
padrão da língua, sem que seja desconsiderada a sua fala original, sem discriminar as variedades nas maneiras de falar.

\section{CONSIDERAÇÕES FINAIS}

A partir deste trabalho, buscou-se, inicialmente, apresentar algumas considerações sobre a variação linguística dentro da perspectiva da História em Quadrinho da Turma da Mônica infantil para a jovem. Pode-se observar que o acréscimo de novas linguagens também produz conhecimento. $E$ as HQs vem contribuindo para a evolução da linguagem, pois são histórias curtas e flexíveis, abordando uma linguagem "caipira" por meio do personagem Chico Bento, o que dá uma veracidade nas produções de Maurício de Souza, sendo observada em várias regiões do Brasil.

A teoria da variação linguística compreende que a mudança linguística é inerente ao próprio sistema, pois um falante ou grupo de falantes podem realizar escolhas de sons, vocábulos ou estruturas na produção da linguagem, partindo do pressuposto que a língua é heterogenia, podendo variar nos seus usos. A variação também está presente nas salas de aula, onde o aluno com sua língua falada cotidianamente é reprimido e humilhado pela sua variação linguística. E o papel da escola consiste em facilitar o acesso das variedades linguísticas que existem desde as diversas variedades rurais isoladas, as áreas urbanas até variedades urbanas padronizadas, abordando as diferenças existentes e ensinando a norma padrão da língua culta do país, dando autonomia ao aluno para expressar-se de acordo com o contexto social a que está inserido.

\section{REFERÊNCIAS BILIOGRÁFICAS}

BAGNO, Marcos. Preconceito linguístico: o que é e como se faz. Rio de Janeiro: Loyola, 2002.

BORTONI-RICARDO, Stella Maris. Educação em língua materna: a sociolinguística na sala de aula. São Paulo: Parábola Editorial 6ª Ed. 2009.

BRESCANCINI, Cláudia Regina. A teoria da variação linguística. In: AGUIAR, Vera Teixeira de; PEREIRA, Vera Wannmacher (Organizadores). Pesquisa em letras. Porto Alegre: Pontifícia Universidade Católica do Rio Grande do Sul, 2007. Disponível em: http://www.pucrs.br/edipucrs/online/pesquisa/pesquisa/artigo9.html Acesso em: 21 out. 2015. 
BRITTO, Luiz P. Leme. Língua e Ideologia A reprodução do Preconceito. In: BAGNO, Marcos. Linguística da Norma. São Paulo: Loyola 2ª Ed. 2004 CALLIAN, Giovana R.; BOTELHO Laura S. A análise linguística e o ensino d alíngua portuguesa: em busca do desenvolvimento da competência discursiva. Revista Educação em Destaque, Vol. 5 N. 01: 1-21. 2014

CAMACHO, Roberto Gomes. Sociolinguística. In: MUSSALIM, Fernanda; BENTES, Ana Christina (Orgs.). 3aㅡ Ed. Introdução à Linguística I: domínios e fronteiras. São Paulo: Cortez, 2003.

GERALDI, João Wanderley. Linguagem e ensino: exercício de militância e divulgação. Campinas: Mercado das Letras, 1996.

JESUS, Ariosvaldo Leal de. Variação linguística e ensino: contribuições da sociolinguística para a sala de aula. In: Encontro interdisciplinar de língua e literatura. Anais eletrônicos... Vol. 3. Itabaiana, 2012.

LUCHESI, Dante. A Teoria da Variação Linguística: um balanço crítico. Estudos Linguísticos, São Paulo, 41 (2): p. 793-805, maio-ago 2012. Disponível em: http://www.gel.org.br/estudoslinguisticos/volumes/41/el.2012_v2_t31.red6_1.pdf Acesso em: 22 out. 2015.

LUYTEN, Sonia M. Bibe. O que é história em quadrinhos? São Paulo: Brasiliense, 1985.

OTHERO, Gabriel de Ávila. Sobre a Evolução Linguística. Revista Eletrônica Letra Magna, Ano 01- n.01 - 2o Semestre de 2004. Disponível em:

http://www.letramagna.com/gabrieldavillaothero.pdf Acesso em: 22/11/15.

POSSENTI, Sírio. Porque (não) ensinar gramática na escola. Campinas: Mercado das Letras. 1996.

QUINTAL. Luciana da Costa. A evolução da linguagem em a Turma da Mônica. Anais do XIV CNLF, p. 109- 124. Rio de Janeiro: CiFEFiL, 2010. Disponível em: http://www.filologia.org.br/xiv_cnlf/tomo_1/completo_tomo_1.pdf Acesso em: 06 nov. 2015.

REVUZ, C. A língua estrangeira entre o desejo de um outro lugar e o risco do exílio. In: SIGNORINI, I. (Org.). Língua(gem) e Identidade: elementos de uma discussão no campo aplicado. Campinas: Mercado das Letras; São Paulo: Fapesp, 1998, p. 213-230.

ROMAINE, S. Language in Society. 2. ed. Oxford: Oxford University Press, 2000. SCHERRE, Maria Marta Pereira; YACOVENCO, Lilian Coutinho. A variação Linguística e o papel dos fatores sociais: o gênero do falante em foco. Revista da ABRALIN. v. 10, n. 3. Curitiba: 2011. Disponível em: http://ojs.c3sl.ufpr.br/ojs/index.php/abralin/article/view/32348/20548 Acesso em: 18 nov.2015. 